Revista Iberoamericana, Vol. LXXI, Núm. 213, Octubre-Diciembre 2005, 993-1013

\title{
HECHOS Y PRINCIPIOS: EL LUGAR DESDE DONDE SE CONSTRUYE LA NACIÓN
}

\author{
POR \\ Ricardo Lionel Costa \\ Danuta Teresa Mozejko \\ Universidad Nacional de Córdoba
}

Convicciones, principios, legalidad, objetivos, bien mayor... son las referencias que aparecen más claramente en superficie esgrimidas en sus discursos por los legisladores de la Sala de Representantes de la Provincia de Buenos Aires para fundar su toma de posición respecto al Acuerdo de San Nicolás. ${ }^{1}$ Intereses mezquinos, provincialismo, demagogia, malicia... son los calificativos empleados para desautorizar la opinión del adversario. El supuesto cultural que funciona en esta forma de proceder, de ninguna manera exclusiva de los legisladores de 1852 sino también fácilmente detectable en discursos contemporáneos, consiste en identificar verdad con convicciones y principios, falsedad con intereses; o al menos: honestidad en la búsqueda de la verdad con convicciones y principios, y deshonestidad, malicia con intereses, lo cual constituye la formulación de un principio de “defensa de la propia cara” (Goffman), pero también el enunciado del camino hacia la verdad. Poder mostrar la persistencia en el tiempo de una manera de pensar es un recurso de autopresentación como hombre honesto, creíble, que seguramente dice la verdad, y se contrapone a quien, al cambiar de opinión, no sería honesto ni creíble y, por eso, seguramente no diría la verdad. Lo que está en cuestión, y de manera íntimamente relacionada, es la doble dicotomía: verdad/falsedad, honestidad/deshonestidad, basada en la también dicotómica diferenciación entre convicción/interés.

Nuestro análisis de los discursos de tres miembros del poder de la provincia de Buenos Aires en las sesiones de la Sala de Representantes de junio de 1852 se ubica expresamente en un registro diferente del enunciado al no poner en juego las dimensiones de verdad u honestidad personales. ${ }^{2}$ Se trata, por el contrario, de ver en qué medida las tomas básicas de posición adoptadas (a favor o en contra del Acuerdo según la visión que se tenga de la historia de la Nación y de su territorio, así como también la posibilidad de reconocer a Urquiza como héroe y otorgarle poderes especiales) y la diversidad de

\footnotetext{
${ }^{1}$ Así se denomina al Acuerdo firmado el 31 de mayo de 1852 en San Nicolás por los Gobernadores de las Provincias Argentinas o sus representantes, al finalizar la reunión convocada por Urquiza, Gobernador de Entre Ríos y vencedor de Rosas en la Batalla de Caseros. En dicho Acuerdo se establecían las pautas para la convocatoria del Congreso General Constituyente y la transición hasta la designación de las autoridades nacionales, todo ello en vistas a concretar lo que se consideraba un objetivo mayor y común: la organización nacional.

${ }^{2}$ Esto no constituye una toma de posición ética sino la adopción de un punto de vista para el análisis.
} 
recursos utilizados para fundarlas (principios, convicciones, legalidad...) guardan una relación significativa con el lugar desde donde hablan los sujetos. ${ }^{3}$ Retomando la expresión de Saussure: "es el punto de vista el que crea al objeto" (49), intentamos contrastar la hipótesis según la cual el lugar desde donde se habla crea el punto de vista.

A los efectos de mostrar con claridad esta relación, necesitamos construir, por una parte, el lugar desde donde habla cada uno de los interlocutores, y sistematizar, por otra, características y matices de los discursos.

El texto del Acuerdo de San Nicolás que el gobernador de Buenos Aires eleva a la Sala de Representantes de la provincia de Buenos Aires el 15 de junio de 1852 junto con un proyecto de ley que autoriza al Poder Ejecutivo a ponerlo en ejecución, contiene, en sus 19 artículos, “las bases del órden provisorio, que muy pronto nos llevará al órden normal que la República debe tener como Nación constituida”. ${ }^{4}$ En dicho Acuerdo se establecen las pautas para la convocatoria al Congreso General Constituyente y la transición hasta la designación de las autoridades nacionales, todo ello en vistas a concretar la organización nacional. La Sala de Representantes inicia, sin embargo, el tratamiento del tema el 6 de junio, al haberse enterado extraoficialmente del mismo por su publicación en los periódicos. ${ }^{5}$

Lo que estaba en juego era, en definitiva, la aprobación o no del Acuerdo por parte de la Sala de Representantes, y la discusión giró sobre dos ejes fundamentales: a) Legalidad, y ésta referida a las facultades sea del gobernador para firmar el acuerdo, sea de la Sala de Representantes para fiscalizarlo y rechazarlo. b) Contenido del Acuerdo mismo, especialmente en lo referente a las facultades que se le otorgaban al director provisorio de la Confederación Argentina. Según nuestra hipótesis, la toma de posición a favor o en contra del Acuerdo expresada en las sesiones de junio de la Sala de Representantes, es producto del lugar de proximidad o distancia en que se encuentra cada uno de los intervinientes en relación a quien constituye el centro real de poder en Argentina en ese momento: el General Urquiza. Las convicciones y principios invocados en los discursos no constituirían, entonces, el fundamento previo de la toma de posición, sino recursos empleados en su justificación. Y el tipo de recursos invocado por cada agente, así como los matices y acentuaciones, guardarían relación con características de la trayectoria de cada uno.

En el presente trabajo centraremos el análisis en los discursos de dos legisladores porteños: Bartolomé Mitre y Dalmacio Vélez Sársfield, y del ministro de Instrucción Pública de la Provincia de Buenos Aires: Vicente Fidel López. La versión que tendremos en cuenta es la de 1853, reproducida por Emilio Ravignani (Asambleas, T.IV), ${ }^{6}$ relato a

\footnotetext{
3 "El lugar desde donde se habla" y "la competencia del agente social" son, en nuestro enfoque teórico, expresiones diferentes de un mismo concepto, a través del cual pretendemos rescatar a quien produce estas prácticas sociales, específicas y diferentes pero prácticas, que son los discursos, sin caer en el individuo ni postular, al modo de Lucien Goldmann, un sujeto transindividual. El desarrollo de nuestro enfoque se puede encontrar en: Costa-Mozejko.

${ }^{4}$ Comunicación del Sr. gobernador a la Sala de Representantes. Ravignani, Asambleas IV: 302.

${ }^{5}$ En el relato de los hechos nos basamos en obras de historiadores que mencionamos en la bibliografía, por ello prescindimos de muchas referencias específicas a pie de página.

${ }^{6}$ El número que aparece al final de cada cita remite a esta edición.
} 
varias voces que comienza el 6 de junio de 1852 con la constitución de los legisladores en sujetos de saber gracias a la información provista por la prensa sobre la firma del acuerdo y culmina con la disolución de la Sala de Representantes, la prisión y el exilio de varios de los oradores por orden de Urquiza el 23 de junio del mismo año. Esta versión del 53 incluye, además: los comunicados que la Legislatura envía al gobernador de Buenos Aires; la nota firmada por éste y sus ministros donde se informa sobre lo actuado; una petición y una exposición de ciudadanos de los días 8 y 11 de junio respectivamente; dos artículos periodísticos, uno de Mitre, publicado en Los Debates el 19 de junio, y otro de Vélez Sársfield, difundido en El Nacional; la renuncia del gobernador y la nota final enviada por Urquiza. En la medida en que estos textos representan las diferentes voces que intervienen en el debate y conforman una historia de conjunto cuyos aspectos conflictivos nos parece importante tener en cuenta, los incluiremos en el corpus de nuestro trabajo.

UN LUGAR EN TRES NIVELES

Las posiciones adoptadas en los discursos encuentran un principio de comprensión y explicación si tenemos en cuenta, al construir el lugar, tres dimensiones o niveles que no solo tienen un peso relativo diferente, sino que, además, intervienen en la producción de características distintas en los discursos sometidos a análisis. Se trata de los vínculos entre Buenos Aires y el interior del país, la centralidad de Urquiza en el sistema de relaciones luego de la victoria sobre Rosas en Caseros y la diversidad de recursos acumulados por los agentes en sus trayectorias, constitutivos de sus respectivas competencias.

\section{LA LUCHA POR EL CONTROL}

\subsection{Ley, fuerza y recursos económicos}

El localismo provincial era, hacia 1850, una realidad que predominaba sobre la organización nacional y no se basaba meramente en el fenómeno de los caudillos locales que reivindicaban la autonomía provincial, sino también en las formas que habían adquirido la producción y circulación de bienes y servicios. ${ }^{7}$ Varios intentos de unidad y organización nacional como los que muestran las constituciones de 1819 y 1826, habían fracasado. El último, el Tratado del 4 de enero de 1831 firmado por las provincias de Buenos Aires, Entre Ríos y Santa Fe, y al que adhirieron luego las demás provincias de la Confederación, también fracasó; las actitudes y decisiones adoptadas por Rosas habrían jugado un papel decisivo en ello. ${ }^{8}$

Buenos Aires concentraba recursos que la ubicaban en una posición dominante respecto del resto de las provincias de la Confederación, y la organización nacional sin Buenos Aires era, y se demostró, inviable. Teniendo en cuenta el mapa económico del país en esa época, el control de la principal fuente de recursos fiscales, la aduana, por parte de

\footnotetext{
${ }^{7} \mathrm{Al}$ respecto, se puede ver Oszlak, Burgin, Cortés Conde y otros, Halperín Donghi.

${ }^{8}$ Cárcano se refiere al Tratado y sus avatares cuando analiza los antecedentes de Caseros.
} 
Buenos Aires, se constituía en la base de su capacidad de autonomía y poder relativo que generaba, además, la posibilidad de financiar un ejército regular propio. La viabilidad de la organización nacional dependía del lugar que se le asignara a Buenos Aires dentro de la misma. Buenos Aires estaba en condiciones de exigir, y así parecería que lo había venido haciendo, la condición de primus inter pares. Las provincias del interior, que no constituían ciertamente una unidad, mantenían, sin embargo, una posición similar sobre todo cuando se trataba de rechazar las pretensiones de Buenos Aires.

La victoria de Urquiza sobre Rosas significaba la victoria militar de las provincias del litoral, ${ }^{9}$ a las que luego se unirían las demás provincias del interior, sobre Buenos Aires y, por lo mismo, la posibilidad de controlar sus recursos económicos y militares, a la vez que de imponer condiciones. ${ }^{10}$ Pero la acción militar contra Rosas fue proclamada como lucha contra la dictadura, fundada en el restablecimiento de la vigencia del Tratado del 4 de enero de 1831 que creaba el compromiso de convocar un congreso general federativo para asegurar las bases legales de la organización nacional (Cárcano 90). El mismo artículo $1^{\circ}$ del Acuerdo de San Nicolás invoca dicho tratado como "Ley fundamental de la República... que será religiosamente observado en todas sus cláusulas” (Ravignani, Asambleas, T.VI 461).

El proceso que se inicia con la victoria de Caseros y durante el cual se llevan a cabo las discusiones en la Sala de Representantes de Buenos Aires, está marcado por la superposición de una situación de hecho que es el control por la fuerza de Buenos Aires por parte de Urquiza, y la reivindicación de su legalidad en el origen (restablecimiento y respeto de una ley fundamental de la República), en el objetivo (convocar el congreso general federativo) y en su desarrollo ("Soberanía, libertad e independencia de cada una de las provincias”. Artículo 2 del Acuerdo de San Nicolás, Ravignani, Asambleas, T.VI 461). Superposición y doble registro que se muestra claramente en el hecho de que a la provincia ocupada militarmente se le permite constituir, mediante elecciones democráticas, sus poderes legislativo y ejecutivo, y que juega sobre la base de que la provincia dominada es la que históricamente ha tenido mayor poder económico y militar, ha mostrado pretensiones de primacía y, al poder elegir ahora a sus autoridades legislativas, lo hace optando mayoritariamente por la lista que no habría sido la preferida del general del ejército que Buenos Aires insiste en reconocer solo como libertador y restablecedor de su soberanía, libertad e independencia.

\subsection{Los discursos}

Si bien los diferentes aspectos del análisis de los discursos pronunciados en el momento en que en la Legislatura de Buenos Aires se discute sobre el Acuerdo de San Nicolás se relacionan de manera indisoluble, a los fines de una mayor claridad en la exposición intentamos distinguir el abordaje de aquellos que parecen vincularse más

\footnotetext{
${ }^{9}$ Económicamente más fuertes que las demás provincias del interior denominadas mediterráneas. Ver nota 7.

${ }^{10}$ Halperín Donghi dice que "Evidentemente Caseros ha puesto en entredicho la hegemonía de Buenos Aires y ha impuesto la búsqueda de un nuevo modo de articulación entre esta provincia, el resto del país y los vecinos” (44).
} 
directamente con cada uno de los tres niveles señalados. Así, sobre el trasfondo de las luchas entre Buenos Aires y el resto del país, nos parece significativo tener en cuenta: 1 . La discusión sobre la naturaleza del documento suscripto en San Nicolás directamente vinculada con la delimitación territorial que implica y 2. La relectura de la historia nacional.

\subsubsection{Género y territorio}

La discusión sobre el carácter del documento firmado en San Nicolás puede vincularse, desde el punto de vista del análisis discursivo, con cuestiones de género -acuerdo o tratado- en el marco de una formación discursiva abarcadora, como lo es el discurso jurídico. Sin embargo, lo que importa aquí no es tanto una cuestión genérica en sí misma sino el hecho de que pone en juego el tema de la soberanía vinculado con una delimitación territorial y, como consecuencia, la definición de quiénes están autorizados a suscribirlo.

Si por tratado se entiende lo que Vicente Fidel López define en su exposición como "un pacto que celebran dos naciones independientes en que se crean deberes y derechos recíprocos” (371), cuando Vélez Sársfield caracteriza inicialmente el documento de San Nicolás como “tratado", establece que las relaciones entre Buenos Aires y la Confederación son relaciones internacionales; en consecuencia, para intervenir en ellas, tal como sucedió en el tratado con Gran Bretaña, se exige la aprobación de la Legislatura porteña. Más adelante, Vélez modifica su idea inicial y se refiere a "un acuerdo entre gobiernos hermanos" (290), al que Buenos Aires debe adherir expresamente y sobre la base de una decisión soberana. La soberanía corresponde a un pueblo cuyo territorio tiene fronteras definidas y fuera de las cuales no es legítima ninguna acción del poder ejecutivo sin autorización de la legislatura. Esta misma definición es la que lleva a negar la legitimidad del poder de Urquiza sobre Buenos Aires en tanto no elegido por el pueblo bonaerense y extraño a su espacio físico y a sus instituciones, y a exigir que la futura constitución sea ratificada por cada una de las provincias. ${ }^{11}$

\footnotetext{
${ }^{11}$ La visión que Mitre y Vélez Sársfield tienen de lo nacional corresponde más bien a lo que Chiaramonte ("En torno a los orígenes...") llama "el concepto contractualista de la génesis del Estado-nación” (306). Según este modelo, la nación, entendida como unidad de gobierno y leyes, surgía a raíz de un acuerdo voluntario entre los pueblos, integrados por vecinos, participantes de "la calidad corporativa de ciudad" (294). Los legisladores, representantes legítimos de esos pueblos -de allí la importancia del respaldo popular que confiriera legalidad a sus actos- eran los encargados de suscribir los contratos que podían tener alcances acotados. Así, Chiaramonte señala un estado de "provisionalidad permanente" (299) que reconoce la unidad cuando alguien coordina la guerra de independencia u organiza un futuro congreso que regularía la relación entre los pueblos. De allí la importancia de los antecedentes legislativos que subraya Vélez en su discurso, como fundamento de la no obligatoriedad de suscribir el acuerdo de San Nicolás. Chiaramonte registra las diferencias en las actitudes de los legisladores bonaerenses y provincianos, según se tratara de formar un ejército nacional, caso en el que Buenos Aires aspiraba a aliarse al resto de las provincias, y el tema de la administración de aduanas frente al cual las provincias sostenían su derecho a compartir beneficios, mientras Buenos Aires defendía su autonomía.
} 
Por su parte, Vicente Fidel López afirma la existencia de un pacto fundamental previo como ley suprema que establece la cohesión entre las partes. Puede suceder que algún acontecimiento particular produzca una ruptura en esa unidad preexistente, en cuyo caso se hace necesaria la intervención de algún agente que la restituya. El concepto de Nación que esgrime López se basa en el reconocimiento de elementos comunes:

\begin{abstract}
Nosotros hemos conservado una misma bandera; un mismo territorio que nos alimenta y dá pábulo al desenvolvimiento de nuestra industria; una misma historia cuenta unas mismas batallas, y unas mismas glorias; y con sacrificios comunes, con la sangre común hemos regado el suelo que habitamos, para hacerlo libre é independiente. ¿Qué quiere decir esto, Señores?... Que tenemos una misma nacionalidad; que existe sobre todas nuestras Provincias un mismo pacto fundamental; que ese pacto es la ley suprema del Estado, que ninguno puede violar ni olvidar; y en fin, que el Gobierno de cada Provincia no bien está instalado, lleva la obligación virtual de hacer cuanto pueda por dar el debido cumplimiento á esa ley que le impone el sentimiento de todos los pueblos Argentinos,... y si esto no se puede negar, no se me niegue tampoco que hay una ley fundamental del Estado, y que eso es buscar la conexión de sus partes y restablecer el pacto nacional (36970)
\end{abstract}

El concepto de nacionalidad que, según Chiaramonte, surge después del 37 e incluye la referencia a una "homogeneidad étnica" (Chiaramonte "En torno a los orígenes..." 288), "presupuestos [...] culturales” compartidos (305) y “connotaciones afectivas”(288) es el que aparece aquí: se trata de "la sangre común” como representación sinecdóquica que alude a la identidad racial de sujetos que reconocen, además, un pasado, un territorio, símbolos y sentimientos comunes. Ese pacto es primero e instala la necesidad de su restablecimiento en caso de suspensión provisoria. A la luz de esta interpretación, San Nicolás no es un tratado entre pueblos independientes, sino un acuerdo que restablece la unidad previa; la intervención del gobernador no constituye un acto ilegítimo en tanto no sancionado por la legislatura, sino que ingresa en el marco de sus facultades específicas en la medida en que no es más que decreto que reglamenta un acuerdo básico; ${ }^{12}$ del mismo modo, la futura constitución, redactada por los representantes de las provincias, no necesitaría ratificación alguna.

\footnotetext{
${ }^{12}$ Sólo dos años después, Mitre sostiene ante la Asamblea General Constituyente del Estado de Buenos Aires, de 1854: "Hay señores, un pacto, un derecho, una ley anterior y superior a toda constitución, así como a cualquiera otra que nos demos más adelante. Hay señores, una nación preexistente, y esa nación es nuestra patria, la patria de los argentinos. El pacto social de esa nación, el derecho, la ley preexistente que debe servirnos de norma, se halla aquí en este mismo recinto. Allí está, es el acto inmortal de nuestra independencia firmada en Tucumán el 9 de julio de 1816 por las provincias unidas en Congreso. Este pacto, anterior y superior a toda ley, como he dicho ya, debe ser el punto de partida de los legisladores" (Citado por Chiaramonte "En torno a los orígenes..." 290). Si bien aquí se hace referencia a "nuestra patria, la patria de los argentinos”, lo que predomina es el rescate de la acción de los congresistas (legisladores) que suscriben el pacto inicial, fundamento de todos los otros acuerdos que seguirán siendo firmados por los representantes del pueblo dentro de una visión predominantemente contractualista de lo nacional.
} 
En el discurso de los diputados, la exigencia de un acto voluntario de adhesión, autorizado por los poderes del estado provincial sobre la base de legislación específica, implica la constitución de Buenos Aires en entidad independiente. Para López, la República es un todo cuyas partes deben concurrir al esfuerzo común en función de un pacto fundamental básico cuya vigencia sólo necesita ser reglamentada en el caso en que se produzca una alteración del orden establecido.

\subsubsection{Lecturas de la historia}

La visión que los diferentes oradores tienen de la historia del país coincide en algunos puntos:

-todos reconocen el año 10 como momento fundante de los procesos históricos que afectaron a la Nación;

-en todos los discursos, el período de Rosas aparece como despótico;

-Urquiza es quien puso fin al gobierno de Rosas;

-se impone, en el presente, una acción decidida en pos de la organización nacional, objetivo compartido por todos.

El discurso de Mitre marca la existencia de dos momentos: el del imperio de la fuerza que genera gobiernos despóticos por un lado y, por otro, la organización nacional, acorde a la ley, como meta. Rosas representa el primer momento, en la medida en que concentra la fuerza en manos de uno solo, mientras que la situación de derecho se caracteriza por el ejercicio del poder por parte del pueblo dirigido por sus legítimos conductores.

Si bien Vélez Sársfield reconoce el año 10 como fecha clave en la historia nacional, en su discurso se destacan los antecedentes legislativos originados a partir del Congreso de Tucumán en 1816. Para él, Rosas es “el más grande tirano” (311), a quien Urquiza ha vencido, instalando así las bases para recuperar la legalidad.

Por su parte, López privilegia las referencias al año 10 y subraya los indicios del carácter nacional de los procesos de la independencia. Así, el primer acto de la revolución fue mandar hombres a las provincias para ayudarles a "libertarse de los mandatarios españoles, para que quedase el vi[r]reinato entero” (387). El espacio de las acciones incluye a las otras provincias; ellas son las que apoyan la campaña de San Martín y de allí proviene el triunfador de Caseros.

Para López, la Nación es un todo, “un solo cuerpo” (386) al que debe subordinarse cada parte; Buenos Aires no es la patria sino que pertenece a ella. Las leyes provinciales son transitorias, no hay una norma orgánica que la transforme en provincia, sino hechos originados en el desorden a partir del año 20 y en modelos de otras naciones que no son base suficiente para la legalidad interior (388). El punto de partida de los procesos nacionales es la unidad; el accidente es la división en tanto ruptura del orden establecido como consecuencia de tendencias particulares, “pasiones mezquinas de localidad” (375) que introducen la anarquía y no el despotismo. El gobierno de Rosas es su consecuencia; "la anarquía levanta siempre tiranuelos, y los que la encabezan en sus triunfos son siempre esencialmente déspotas” (376). Dentro de esta visión de la historia, los acontecimientos son hechos consumados cuya validez deriva no tanto de una legalidad previa inexistente 
sino de su orientación con respecto a la restitución del orden primero. Los males del país radican en la anarquía y no en el despotismo; en la división y no en la concentración del poder.

En la historia iniciada en 1810, todos los oradores reconocen un período de vigencia de antivalores representados por Rosas; pero mientras los diputados Mitre y Vélez Sársfield lo definen como despotismo y tiranía, en tanto tiempo de concentración de un poder no delegado por el pueblo, para López el mal es la anarquía como dispersión, sucesión de acciones convulsivas orientadas por pasiones disociadoras. Mirada la historia nacional desde las proximidades del poder, las permanentes dificultades por lograr la organización nacional aparecen como producto de los provincialismos ciegos y de la anarquía; la misma historia y el desencuentro nacional son considerados resultados del despotismo por parte de quienes rechazan legalizar el poder que otorga el Acuerdo a Urquiza. Para López el gobierno de Rosas es anárquico en sus orígenes; para Mitre y Vélez Sársfield es la representación clara del despotismo y sus consecuencias. Sobre esta base se definen también los caminos hacia la organización nacional: gobierno de los representantes legítimos del pueblo como imperio de la legalidad, que deberán ratificar la constitución que se sancione con independencia del poder de Urquiza, basado en la fuerza militar, por oposición a la importancia que le acuerda López a la fuerza como factor de vínculo en una opinión pública dividida y anárquica.

La contradicción objetivamente instalada se muestra de manera clara en los discursos de los tres agentes seleccionados como defensa de la legalidad, de principios, contra la posible reinstalación de un gobierno despótico -por más que pueda ser de transición y por pocos meses-, de garantías legalmente establecidas contra la posible arbitrariedad por una parte, o de facultades especiales a quien tiene el poder de hecho y que, actuando en defensa de la legalidad como lo había demostrado, estaría así en condiciones de asegurar el éxito del proceso hacia la organización nacional neutralizando cualquier intento anárquico que, como en el pasado, pudiese atentar contra el logro del objetivo común.

Sin embargo, no es la puja Interior / Buenos Aires, igualdad de condiciones / primacía en el marco de la organización nacional, la que define las posiciones a favor o en contra del Acuerdo de San Nicolás, aun cuando constituya la base objetiva presente en la elaboración de los discursos una vez adoptada la posición básica a favor o en contra del Acuerdo. En efecto, dos de los interlocutores (Vicente Fidel López y Bartolomé Mitre) son nativos de Buenos Aires, y el tercero (Vélez Sársfield), nacido en la provincia de Córdoba, se instaló en Buenos Aires en 1823 apenas recibido de abogado y allí realizó su trayectoria de reconocido jurista. Vicente Fidel López, el más “porteño” de los tres porque fue el único que nació, vivió, se formó como abogado y ejerció su profesión en Buenos Aires antes de irse, bajo el gobierno de Rosas, al exilio, estuvo a favor del Acuerdo que los otros dos interlocutores rechazaron por razones de principios y como contrario a la legalidad. El factor que, a nuestro entender, permite explicar la adopción de la posición básica (a favor o en contra) respecto al Acuerdo se encuentra en otra de las dimensiones constitutivas del lugar desde donde hablan los agentes: la proximidad / distancia respecto a Urquiza. 


\section{LA PROXIMIDAD AL PODER}

\subsection{Elegidos y excluidos}

Todo parece indicar que entre Caseros (febrero de 1852) y las sesiones de junio del mismo año de la Sala de Representantes, las relaciones con el general vencedor, que pasaba a concentrar de hecho el máximo de poder y se convertía, por lo mismo, en quien distribuía los beneficios y fijaba las reglas de acceso al poder-incluso al decidir que en Buenos Aires se llegase, y en forma inmediata, a la constitución del poder legislativo mediante elecciones democráticas-, adquirieron la forma de un triple círculo concéntrico, cada uno de los cuales incluía distintos actores, entre los cuales parece importante mencionar los siguientes:

- En el primer círculo, el más próximo a Urquiza, estaban sus “consejeros de confianza: Pujol, Derqui, Pico, López, ${ }^{13}$ de la Peña, Gorostiaga” (Cárcano 190). Este sería probablemente el círculo al que se refiere V.F.López cuando en su carta del 15 de abril de 1858 dice: "Otros señores como yo, hablaban diariamente con el general Urquiza” (318).

- En el segundo, los invitados a algunas reuniones especiales e importantes (de las que participaban ciertamente integrantes del primer círculo) como la del 14 de abril (Alsina fue invitado y Vélez Sársfield ignorado), que se realizó a pocos días de las elecciones legislativas de Buenos Aires (11 de abril), y la del 5 de mayo (entre los “notables" -De Marco 127- fueron invitados Alsina y Vélez Sársfield). ${ }^{14}$

- A B. Mitre lo ubicaríamos recién en el tercer círculo porque no consta que haya formado parte de “los consejeros”, los invitados especiales o los “notables”. No es por ello totalmente ignorado por Urquiza quien, durante el mismo mes de febrero de 1852, lo convocó a Palermo para comunicarle personalmente su ascenso al grado de coronel de artillería de Buenos Aires. ${ }^{15}$

Los López estuvieron entre los elegidos de Urquiza quien, al día siguiente de Caseros, designó a Vicente López y Planes como gobernador provisional. El 23 de marzo le indicó al mismo Vicente López que creara el Ministerio de Instrucción Pública y designara en el

\footnotetext{
${ }^{13}$ Por la información disponible en los textos de historiadores que se refieren a este período, y especialmente en Cárcano, deben ser incluidos en este círculo tanto Vicente López y Planes (padre), gobernador designado por Urquiza, cuanto el hijo Vicente Fidel López, ministro de Instrucción Pública designado por su padre a sugerencia de Urquiza.

${ }^{14}$ En la disputa entablada en 1858 mediante cartas a periódicos por varios de los participantes a esta reunión acerca de la verdad de la posición que cada uno de ellos habría adoptado en la misma respecto al proyecto de Acuerdo a llevarse a San Nicolás, Pico y Vélez Sársfield ubican en una fecha diferente un hecho importante: la presentación en la Sala de Representantes, por parte del primero, de un proyecto en el que proponía acordar al General Urquiza un voto de gratitud por haber liberado a Buenos Aires del tirano, y designarlo encargado de las relaciones exteriores, negocios de paz y guerra y, en general, de todos aquellos que competen a la autoridad nacional. Esta presentación habría sido realizada el 3 de mayo según Vélez Sársfield (es decir, antes de la reunión de notables convocada el 5 de mayo por Urquiza), y el 10 de mayo según Pico. Tampoco hay unidad de criterio entre diversos historiadores al respecto.

${ }^{15}$ Mitre tuvo una participación directa en la Batalla de Caseros al mando de un escuadrón, bajo las órdenes del coronel José María Pirán (De Marco 107).
} 
mismo a su hijo el Dr. Vicente Fidel López (Piccirilli 87). La elección y proximidad de los López se reafirmó de una manera muy clara y decidida en la reunión que convocó el General el 14 de abril, tres días después de la elección de los miembros de la Sala de Representantes. Esta, que debía designar al gobernador propietario, estaba compuesta en su mayoría por integrantes de la lista no preferida por Urquiza (entre ellos Mitre y Vélez Sársfield). Los Debates, dirigido por Mitre, había propuesto como gobernador a Valentín Alsina, quien tenía la mayor probabilidad de ser elegido.

A esa reunión invitó también a Alsina, entonces ministro de Vicente López, pero no a Vélez Sársfield, que se habría incorporado a la comitiva sin lograr, sin embargo, ser invitado por Urquiza al almuerzo. A la hora de los brindis, y a pesar de lo expresado por Alsina al proclamar al General Urquiza como futuro presidente de la República, este manifestó directamente que Vicente López debía continuar como gobernador. Urquiza eligió a López, postergó a Alsina y excluyó a Vélez Sársfield (integrante de la misma lista con Alsina y Mitre). El $1^{\circ}$ de mayo, la Sala de Representantes votó mayoritariamente por Vicente López como gobernador.

Cuando Urquiza convocó el 5 de mayo a un grupo de “notables” para discutir el texto de lo que se llevaría como propuesta de acuerdo a la reunión de los gobernadores en San Nicolás, Vélez Sársfield -ya reconocido jurista en esa época-también fue invitado. No así Mitre.

Independientemente de la discusión entablada en 1858 entre varios de los protagonistas de esta reunión acerca de la verdad de la posición adoptada por cada uno respecto al texto, parecería existir acuerdo en que todos los participantes habrían rechazado el primer punto de la propuesta de Pujol (ministro de Corrientes) sobre la capitalización de Buenos Aires, y que Urquiza habría también manifestado su acuerdo con las opiniones de Alsina y Vélez Sársfield, solicitando que se redactara a partir de ellas una nueva propuesta para tratarla en una próxima reunión.

Vélez Sársfield manifesta en 1858 que, luego de esa reunión, Urquiza rompió tanto con él como con Alsina. Este dice algo similar (Cárcano 334, 345). Todo indicaría que fueron excluidos de la proximidad de Urquiza que no se volvió a reunir con ellos. El 10 de mayo, ${ }^{16}$ el diputado Francisco Pico, integrante del grupo de los “consejeros” de Urquiza, propuso en la Sala de Representantes “un voto de gracias al libertador” y su nominación como "encargado de las relaciones exteriores, negocios de paz y guerra y en general todos aquellos que competen a la autoridad nacional” (De Marco 127). La comisión de negocios constitucionales, presidida por Vélez Sársfield, aconsejó aprobar únicamente el voto de gracias, y la Sala lo hizo por unanimidad. Esto significaba un rechazo explícito, por parte de la Sala de Representantes de Buenos Aires, de otorgar a Urquiza una facultad que implicaba reconocerle autoridad legal sobre Buenos Aires como se la habían acordado sobre el país los gobernadores de las provincias firmantes del acuerdo de enero de 1831, y le encargaría luego el Acuerdo de San Nicolás. Antes de la reunión en San Nicolás también renunciaría Alsina como ministro de Vicente López. A San Nicolás viajaban, acompañando al gobernador, Francisco Pico y Vicente Fidel López.

${ }^{16}$ Sobre el problema de la fecha exacta en la que Pico hace su propuesta, ver nota 14. 
Nuevamente fueron excluidos de la proximidad de Urquiza Alsina, Vélez Sársfield y Mitre.

Ponemos el acento en los hechos que van mostrando la construcción progresiva del mapa de las posiciones de proximidad / distancia respecto a Urquiza, en función de constatar la validez de nuestra hipótesis según la cual las tomas de posición por parte de cada legislador en la Sala de Representantes respecto al texto del Acuerdo de San Nicolás, más que como resultado de convicciones y principios, se explicaría por la posición en relación a Urquiza, posición que, además, todo lleva a ver como producto de decisiones y/o reacciones de quien tiene el poder real -Urquiza- y/o de su entorno inmediato. ${ }^{17}$

\subsection{La construcción discursiva de los personajes}

Si partimos de esta hipótesis, según la cual las tomas de posición de los agentes se organizan a partir de sus posiciones alrededor de la figura de Urquiza, el modo como los diferentes discursos representan a los personajes y los vínculos entre ellos parece particularmente significativo como estrategia para fundamentar una toma de posición que, sin embargo, no encuentra su razón suficiente más que en la distancia de cada agente respecto a Urquiza, a quien, de todas maneras, por su poder, no pueden ignorar ni enfrentar de manera directa. Para abordar este aspecto tendremos en cuenta todos los textos del corpus que conforman un relato a varias voces y en cuyo diálogo podemos percibir aspectos importantes.

\subsubsection{Urquiza como héroe}

A tal punto está presente en el proceso la centralidad de Urquiza y su poder ${ }^{18}$ basado en la victoria y la fuerza, que los mismos legisladores que rechazan el Acuerdo invocando cuestiones de legalidad (sobre todo Vélez Sársfield) o de principios (especialmente Mitre) dejan sin embargo a salvo, de manera explícita, la persona de Urquiza.

Tanto Mitre como Vélez Sársfield y López coinciden en reconocer en Urquiza una figura heroica. Si para todos ellos el gobierno de Rosas representa la tiranía y la vigencia de antivalores, con la victoria de Caseros, Urquiza le pone fin a esa situación. Esto le vale el calificativo de "general libertador" (309) en boca de Mitre, restablecedor de la paz y

\footnotetext{
${ }^{17}$ Los reiterados intentos por ganarse la simpatía y voluntad de Urquiza en el período que estamos analizando que Vicente F. López le atribuye tanto a Alsina como a Vélez Sársfield no parecen ajenos a la realidad si tenemos en cuenta algunos de los hechos antes consignados. Sin embargo, fueron dejados de lado por el general luego de la reunión del 5 de mayo en Palermo. “¿Por qué rompía (Urquiza) con nosotros (Vélez Sársfield y Alsina) en términos de no volvernos a ver jamás después de la conferencia tenida en Palermo?”, se pregunta Vélez Sársfield en 1858 (Cárcano 334). Después de la reunión de Palermo "...nadie volvió ya a hablarme una palabra del asunto; empezaron a recatarse de mí” expresará el mismo año Alsina (345).

${ }^{18}$ Empleamos aquí el concepto de poder y de autoridad en el sentido definido por Weber (43), entre los cuales existe una diferencia clave que Dahrendorf sintetiza claramente diciendo que “...mientras que el poder es una mera relación de hecho, la autoridad es una relación legítima de dominación y sujeción. En este sentido la autoridad puede ser considerada como un poder legítimo” (166).
} 
tranquilidad según Vélez, y también “libertador” (383) para López. En todos los casos, la victoria se dio en el campo de batalla gracias a la fuerza como forma de competencia específica de aquel cuyo apellido aparece siempre acompañado del grado militar: "general Urquiza”.

Los problemas surgen no en relación a este aspecto del pasado, cuyo reconocimiento y valoración son unánimes, sino sobre el presente y el futuro. Suscribir el Acuerdo de San Nicolás implica, por un lado, otorgarle a Urquiza los atributos de Encargado de Relaciones Exteriores de la Confederación, ${ }^{19}$ incluida Buenos Aires, mientras se convoca el Congreso Constituyente que habrá de fijar las modalidades de elección del presidente, aunque se prevé que el mismo Urquiza será designado para el cargo. Y aquí surgen los mayores conflictos, planteados en términos de enfrentamiento entre poderes.

Mitre es quien más insiste en el hecho de que no se trata de desconfiar de la persona misma de Urquiza, sino de los temores que suscita el hecho de investirlo de un poder excesivo, concentrado en un solo individuo; ello implicaría darle mayores atribuciones que las del mismo Rosas, cualquier presidente y mismo congreso. El abuso en el ejercicio de las facultades otorgadas llevaría a homologar al héroe con el antihéroe vencido: "Si abusa de esas facultades, será lo que se llama un poder tiránico, como lo fue el de Cromwell y el de Rosas” (315).

Vélez Sársfield coincide con Mitre en afirmar la necesidad de que Urquiza abandone la espada, a la vez que objeta la concentración del poder que anularía las facultades del legislativo y la autonomía provincial. También critica la posibilidad de que la constitución sea votada por una cámara dependiente del encargado de relaciones exteriores cuyo cargo corre el riesgo de ser vitalicio. El uso de la fuerza excesiva por parte del ejecutivo ya tiene antecedentes en la historia del país, según Vélez:

Los gobiernos fuertes son precisamente los que han embarazado las constituciones que han dado los Cuerpos nacionales. El Congreso que declaró la independencia de la nacion y que dió la constitución de 1819, ¿cómo y porqué acabó? Un Gobernador de Buenos Aires prendió á todos los Diputados, y los mandó procesar, tan solo porque tenía fuerza para hacerlo. (361)

Nuevamente aparece una manera indirecta de referirse al propio temor que anticipa lo que sucederá al final de las sesiones, cuando Urquiza disuelva la legislatura, encarcele y procese a varios diputados. Las estrategias de un decir indirecto, de mandatos que se disimulan detrás de aserciones y actos de fe o de remisiones al pasado que aparecen como comparaciones con el presente solo cuando se tienen en cuenta todos los discursos que integran las actas del 53, aluden a un conflicto en el que los diferentes enunciadores se representan a sí mismos en situación de riesgo ante un poder que es superior.

Vicente Fidel López intenta contrarrestar estas opiniones desplazando el origen del poder de Urquiza: este no depende de las facultades que le otorga el Acuerdo de San Nicolás sino del triunfo sobre Rosas. Además, se trata de una situación transitoria y una “imperfección necesaria” (388), dada la inexistencia de leyes que organicen la nación. La

${ }^{19}$ Además del control de la aduana, el mando del ejército, la defensa de la paz interior, etc. 
lectura que hace López de la historia nacional lo lleva a ver problemas no en gobiernos despóticos o tiránicos, sino en la anarquía que, como riesgo en el presente, exige la constitución de un poder que una la ilustración de los representantes del pueblo y la fuerza militar de Urquiza que los legisladores, por su parte, pretenden anular.

\subsubsection{La construcción del rol y de la legitimidad de los oradores}

Si Urquiza está en Palermo con sus tropas, Mitre y Vélez Sársfield convocan al pueblo de Buenos Aires al interior del recinto y, aunque el segundo prefiera las sesiones secretas, los legisladores fundan su legitimidad en su relación con el pueblo que representan a la vez que deslegitiman la figura de Urquiza por el origen de su poder, ajeno a la voluntad popular.

La construcción que hace Mitre de sí mismo lo convierte en representante de la razón y de las ideas frente a lo que llama "fuerza bruta” atribuida a Rosas y previsible en Urquiza si asume poderes extraordinarios. Según Mitre, la fuerza en manos de uno se convierte en despotismo, como forma de gobierno que asumiría el entrerriano si se firmara el tratado de San Nicolás (323); por el contrario, la fuerza en manos de todos corresponde al estado de derecho. De allí la insistencia de Mitre en la representatividad. Mientras el poder de Urquiza se apoya en el manejo de las bayonetas y corresponde al ejercicio de la voluntad individual, no controlada por poder alguno y superior a la de los legisladores y el pueblo, Mitre se constituye en mandatario de hombres que viven en un territorio y organizan su acción en base a leyes. Solo así es posible afirmar la dignidad humana para lo cual ofrece al pueblo su brazo: "La moral pública está caída: es necesario levantarla. Débil y flaco como es, yo le ofrezco mi brazo para que se apoye en él y lance contra sus asesinos la sublime protesta que Jesu-Cristo lanzó á los verdugos, cuando se negó a humedecer sus labios en la esponja empapada en hiel que le presentaban con mano sacrílega” (319-20).

Mandatario del pueblo, Mitre es su dirigente y salvador. Su relación con el mandante presenta, sin embargo, matices dignos de ser tenidos en cuenta. Por una parte, aprueba la agitación del pueblo en la sala de sesiones como necesaria, pero asume el rol de dirigente ilustrado cuando lo convoca a través del periódico y se convierte en transmisor de la verdad, asistido por el Espíritu Santo. ${ }^{20}$ Mitre informa al pueblo sobre el exceso de poderes

\footnotetext{
${ }^{20}$ Hilda Sábato, quien estudia las movilizaciones públicas en Buenos Aires entre 1860 y 1880, afirma que la intervención pública para expresar opinión o presionar por alguna causa era frecuente y, a la vez, “desde el poder se atendía a las señales que provenían de la esfera pública en la medida en que, como en otras sociedades en proceso de modernización, 'políticamente... la noción de «público» se convirtió en la base de un nuevo sistema de legitimidad en una cultura política transformada"” (Sábato cita a Keith Baker 483). "La convocatoria a cualquier movilización era el paso previo a la culminación de toda una actividad desarrollada a favor de una causa determinada por sus promotores y la iniciativa provenía de ese entramado de instituciones de la sociedad civil, desde donde se planteaba el problema y se proponían la estrategia y los mecanismos de la movilización” (487) "El principal medio de convocatoria era, en todos los casos, la prensa" (489) "En un momento en que, [...] existía una fuerte preferencia por las concepciones unitarias del cuerpo social, se consideraba que la opinión pública expresaba la unanimidad de intereses del pueblo por encima de las nocivas divisiones políticas, peyorativamente consideradas facciosas. Ese pueblo, en estricta comunión
} 
otorgados a Urquiza a quien posiciona en el ámbito de los valores individuales en perjuicio de los colectivos; en el espacio de la fuerza capaz de convertirse en tiranía por oposición a la defensa de la dignidad humana, la libertad, la justicia, como valores que él mismo garantizará al pueblo en tanto dirigente esclarecido que representa la autoridad de la razón y la idea. Mitre informa y moviliza al pueblo para hacerle saber que la cesión de los poderes que demanda el Acuerdo de San Nicolás va en contra de la naturaleza misma; es mandatario y dirigente, conoce los principios que sustentan el orden, "los principios generales de buen gobierno" (314), el derecho escrito y el derecho natural. Mitre propone definiciones ("Poder dictatorial, Señores, es...” "Poder irresponsable es...” "Poder despótico es...” 314) cuyo reconocimiento es del orden de lo necesario en tanto surge de un intérprete de la norma que se erige como incuestionable (“es necesario reconocer conmigo...” 315). Convoca al pueblo al lugar de las sesiones, lo define como mandante, pero a tal punto es dueño de la verdad que su juicio sobre el Acuerdo surge de una única lectura y sin necesidad de escuchar otras voces; su insistencia en la unanimidad con los pares y su manera de valorar la intervención del público naturalizan su competencia y hacen que su sola conciencia, orientada por la justicia, sea garante de la verdad, a la vez que él mismo se perfila como constructor de la dignidad de los pueblos. Lo que busca es evitar el peligro de un gobierno no controlado por la ley, por nosotros, y el peligro de que ese poder nombre y remueva a los legisladores.

La posición institucional de Vélez Sársfield es equivalente a la de Mitre en tanto ambos son legisladores de la provincia de Buenos Aires y coinciden en sostener que el fundamento de su autoridad está en la voluntad popular que elige a sus representantes, como lo afirma en el artículo publicado en El Nacional. Vélez Sársfield es quien más insiste en la relación entre pueblo, poder y territorio. El pueblo soberano al que alude permanentemente es el de la provincia de Buenos Aires; por eso el gobernador no tiene atribuciones para actuar fuera de sus límites; a la vez, Urquiza, héroe momentáneo del triunfo militar en Caseros que termina con la tiranía de Rosas, corre el riesgo de reproducir la historia del antihéroe en la medida en que no representa al pueblo bonaerense -no ha sido elegido por él, no atiende a la opinión pública- y proviene de un territorio diferente. En el artículo de El Nacional, "los héroes que han perdido su mérito” (312) aparecen como hijos de "poderes tenebrosos", ajenos al pueblo, sometidos a intereses personales y defendidos por el poder de las armas (312); en una palabra, son los antihéroes que se oponen a la opinión pública y al "nosotros” que la representa legítimamente.

Si los legisladores convocan al pueblo a la sala de sesiones y lo convierten en fundamento de la propia legitimidad frente al poder de Urquiza, Vicente Fidel López construye su sistema de relaciones de manera diferente. Ante todo, y frente a la convocatoria de los diputados que solicitan información sobre el Acuerdo, fundamenta la legitimidad de su rol en su dependencia con respecto a una autoridad superior: el Gobernador Propietario de la Provincia de Buenos Aires; por lo tanto, ni siquiera los legisladores

entre sus partes, encarnaba a la nueva comunidad política y constituía, por lo tanto, la base indispensable para la construcción y el ejercicio del poder” (511). Es posible leer entonces, la referencia al apoyo popular en Mitre y a la unanimidad de los pares legisladores, una suerte de “naturalización/universalización” de la propia opinión. 
tienen autoridad para citarlo. Sin embargo, participa luego de la discusión y explicita diferencias notables con respecto a los discursos de Mitre y Vélez Sársfield.

López funda su competencia en el hecho de haber nacido en Buenos Aires y de haber sido testigo presencial de lo que ocurrió en San Nicolás; también en el conocimiento que tiene de la historia y de la legislación nacional. Si los legisladores se apoyan en la opinión pública, para López la muchedumbre que actúa convulsivamente es tan negativa como la anarquía. El ministro de Instrucción Pública prescinde de la presión popular en la sala y acusa a los diputados de lisonjearla con la mentira; la invocación, en esas circunstancias, de la representatividad como fundamento de legitimidad de Mitre y Vélez Sársfield es para López demagogia:

\begin{abstract}
En el curso de esta discusión he notado que hay quien se permite interrumpir la voz de los oradores con señales de aprobación y reprobación según el impulso de sus propias pasiones. Bien pues, ya que eso existe, y ya que yo no lo puedo remediar, me honro en declarar bien alto, que semejantes manifestaciones no tendrán ninguna influencia sobre mi espíritu. Declaro también, que por educación y por principios jamas he ambicionado honores ni bienes que traigan su origen de la adulación, ni de la lisonja dada al poder, bien sea que se llame tiranía, bien sea que se llame muchedumbre. En ese sentido no deseo la popularidad. (368-9)
\end{abstract}

López prescinde del esquema de delegación del poder. A los pueblos les falta inteligencia, son atrasados y no comprenden ni usan adecuadamente la libertad. Para él, "el espíritu público [...] es la actividad reglada de la opinión, en el movimiento regular y tranquilo de las fuerzas colectivas y no en ese fatalismo de las convulsiones...” (393). La unidad y el orden se construyen por asociación de la "opinión ilustrada” con la fuerza, de los dirigentes, sujetos de saber, con la fuerza militar que superarán la acción disociadora de la opinión pública. Los males que aquejan al país derivan de la división y no de la concentración del poder; por el contrario, esta última, como circunstancia transitoria, garantizará la organización nacional.

\title{
2.3. Hechos y principios
}

Si lo que está en juego es asegurar la transición hacia la organización nacional y la persona de Urquiza es una garantía, curiosamente para los próximos al general, ${ }^{21}$ que no hay razones suficientes para descalificar como "personas sin principios”, el Acuerdo de San Nicolás no plantea problemas y asegura el logro del objetivo común; para los desplazados, en cambio, constituye una afrenta a principios y leyes que, aun cuando sea por un breve tiempo, sus convicciones les impiden aceptar.

Urquiza busca asegurar un proceso hacia la organización nacional dentro de la legalidad pero no parece aceptar que se ponga en cuestión su poder; San Nicolás da el paso adecuado en este sentido, legalizando su poder y convirtiéndolo en autoridad legítima. Para los legisladores no está en juego la persona del general. Sin embargo, para los que

\footnotetext{
${ }^{21}$ Pico, legislador de Buenos Aires, integrante del grupo de “consejeros de Urquiza”, defiende el acuerdo al igual que López.
} 
defienden el Acuerdo, unir la legitimidad legal al poder real significa aumentar la centralidad de quien los ha elegido; para quienes se oponen, aquellos cuyo único poder surgió de los votos como integrantes de una lista no bendecida por Urquiza, implica no solo sumar poder en manos de quien los ha excluido, sino además hacerlo mediante la propia privación al transferirle facultades (como la de encargarle las relaciones exteriores) hasta el momento reservadas a la provincia. Su propio poder no viene de Urquiza, sino del pueblo, y a este movilizan Mitre y Vélez Sársfield mediante artículos que publican en Los Debates y El Nacional diciendo que el Acuerdo debe ser rechazado porque "establece una dictadura inaceptable”, instaura un poder "nacido fuera del pueblo" y que "el pueblo no hubiera votado” (309 y 311). El recinto de la Sala de Representantes está colmado por el pueblo que aplaude a Mitre y Vélez Sársfield mientras repudia a Vicente Fidel López que, incluso, tiene dificultades para retirarse ileso de la Sala de Representantes luego de su discurso del 22 de junio. En Palermo está Urquiza con el ejército, y el 23 asume el gobierno de la provincia para "salvar la patria de la demagogia, después de haberla libertado de la tiranía” (De Marco 134), y dispone la prisión y destierro de varios legisladores, entre los cuales están Mitre y Vélez Sársfield.

Lo dicho nos permite ver que la adopción de una actitud y decisión a favor o en contra del acuerdo de San Nicolás encuentra su explicación más consistente en la distancia con respecto a Urquiza por parte de cada uno de los interlocutores considerados. Tal toma de posición es presentada, por quienes se oponen, como fundada en principios, convicciones y respeto a la ley que, por otra parte, según son formulados, coinciden con los intereses de Buenos Aires cuyo pueblo los votó: defender sus derechos y autonomía rechazando aceptar la autoridad de Urquiza ${ }^{22}$ y reduciendo su papel al de gobernador de Entre Ríos que liberó a Buenos Aires de la tiranía de Rosas, hecho por el cual la Sala de Representantes aprueba un voto de agradecimiento, al mismo tiempo que rechaza encargarle las relaciones exteriores. Pero, insistimos, de acuerdo a los elementos puestos en juego, no son ni las convicciones ni la defensa de los intereses de Buenos Aires los que proporcionan una explicación suficiente de la posición adoptada por cada agente respeto al Acuerdo. Esta es producto del lugar de proximidad/distancia de cada uno respecto a Urquiza, aunque se

\footnotetext{
${ }^{22}$ Mantener el control de las relaciones exteriores ha sido en la historia del país un factor clave de manifestación de la "soberanía, libertad e independencia de cada una de las provincias" (términos usados en el articulo 2 del Acuerdo de San Nicolás, Ravignani Asambleas, T.VI 461). Ponerlo en manos de alguien ajeno a la provincia, significaba reconocer su autoridad, aún cuando pudiese verse legitimado, especialmente ante los ojos de las provincias del interior, como un gesto necesario en vistas a la organización nacional. El 6 de abril de 1852, antes de las elecciones legislativas de Buenos Aires, en Palermo (residencia de Urquiza luego de Caseros), los gobernadores y/o representantes de las cuatro provincias del litoral signatarias del pacto federal de 1831 (Buenos Aires, Entre Ríos, Santa Fe y Corrientes) firmaron un protocolo por el que se encargaba a Urquiza el manejo de las relaciones exteriores de la República hasta la reunión del congreso general constituyente. El texto del Acuerdo de San Nicolás da por sentada la legitimidad de estas facultades otorgadas el 6 de abril refiriéndose permanentemente, desde la misma introducción, al "Excmo. Señor Encargado de las Relaciones Exteriores de la República Brigadier General Justo José de Urquiza”. La Sala de Representantes de Buenos Aires, sin embargo, una vez constituida, no aceptó encargar a Urquiza las relaciones exteriores a pesar de lo firmado por el gobernador provisorio el 6 de abril.
} 
presente como fundada en convicciones y principios, ${ }^{23} \mathrm{y}$ adquiera mayor fuerza por inscribirse dentro de la defensa de los derechos de Buenos Aires en el marco de su histórica puja con las provincias del interior.

\section{3. ÉNFASIS Y DIFERENCIAS SEGÚN COMPETENCIAS}

La posición en relación al centro del poder ocupado por Urquiza nos permite explicar que agentes diferentes, aun siendo funcionarios o legisladores porteños, adopten posiciones opuestas sobre la aprobación del Acuerdo de San Nicolás, así como una serie de estrategias discursivas ligadas a convicciones, principios y legalidad respecto a componentes relativos al proceso de transición en unos, a los requisitos necesarios para lograr el objetivo superior y común de la organización nacional en el marco de una constitución en otros. Sin embargo, hay estrategias que pasan por énfasis y modos de argumentación diferentes y que no encuentran en los elementos antes expuestos un principio de explicación pertinente. Necesitamos para ello poner en juego una tercera dimensión o nivel en la construcción del lugar desde donde hablan los autores de los discursos: ciertas competencias diferenciadas según trayectorias. ${ }^{24}$ Para verlo con más claridad, tendremos en cuenta dos agentes que se pronunciaron contra el Acuerdo de San Nicolás: Mitre y Vélez Sársfield.

Mitre, el primero en hablar en la sesión del 21 de junio en que comenzó a discutirse el Acuerdo, explicita como fundamentos de su convicción contraria a la "admisión del tratado", principios que en definitiva deben ser respetados para que la autoridad sea legítima y no poder despótico, como los de libertad, justicia, control del ejercicio de la autoridad por una autoridad superior y, en última instancia, por parte del pueblo "fuente de todo poder y de toda razón” (314), derecho natural y escrito, dignidad, la naturaleza de las cosas, el modo de ser de la especie humana y de la sociedad tal cual está organizada. Luego añadirá: "Yo no me ocupo de las personas ni de sus intenciones; toda mi atención está fija en los principios que he considerado, no en abstracto sino en su aplicación a la situación actual, porque son principios que nunca caducan, y cuya discusión y aplicación en todo tiempo es oportuno" (322-3).

Vélez Sársfield, en cambio, centrará el peso de su argumentación en aspectos legales. Las facultades que se abrogó y que nunca tuvo el gobernador de Buenos Aires para firmar el Acuerdo en San Nicolás y las facultades legislativas que asumieron, sin tener, los gobernadores que firmaron el acuerdo. Los poderes que se otorgan a Urquiza destruyen los poderes públicos de la provincia y la privan de sus poderes constitucionales, y "en mucha parte corresponden al Cuerpo Legislativo de la Nación” (358 y ss.). Se muestra conocedor de los antecedentes históricos y legislativos del país, del origen, objeto y jerarquía de los poderes en el orden político, cita la experiencia de otros países, y de la misma Argentina en 1826, en cuanto al proceso de elaboración, sanción y aceptación de la constitución nacional.

\footnotetext{
${ }^{23}$ De ninguna manera se pone en juego aquí la dimensión de “conciencia”, "buena o mala fe”, etc., por parte de los autores de los discursos.

${ }^{24}$ Empleamos "trayectoria” en el sentido elaborado por Bourdieu, y por contraposición a una mera biografía.
} 
Si Mitre apoya su discurso en una defensa de principios y definiciones ("Poder dictatorial, Señores, es...” "Poder irresponsable es...” "Poder despótico es...”, 314), Vélez Sársfield justifica su posición en la referencia al derecho escrito desde la independencia en $1816 \mathrm{y}$ al derecho consuetudinario, ambos considerados como fundamentos de cualquier acto legislativo. Entre sus pares, Vélez es quien más explícitamente apela al marco jurídico como base de sus opiniones; su modo de argumentar se apoya en las normas que rigen el equilibrio entre los poderes y la representatividad. Esta visión de lo legítimo en cuanto apoyado en leyes impone al discurso de Vélez una modalidad marcadamente deóntica que condiciona el deber y el poder hacer de las autoridades políticas, aunque al referirse a Urquiza eluda a su rol de mandante para privilegiar su carácter de sujeto de creencia, como lo hemos visto.

El discurso de Vélez Sársfield pone en evidencia la especificidad de una competencia acumulada en toda su trayectoria. Hijo de un autodidacta con fama de experto jurista, obtuvo su matrícula de abogado en 1822 (a los veintidós años). Radicado inmediatamente después en Buenos Aires, comenzó en 1824 su experiencia legislativa en el Congreso Nacional convocado por Bernardino Rivadavia como diputado por San Luis. En 1826 abrió su estudio de abogado, y esta actividad sería central en toda su vida, aunque entrecortada por problemas durante el gobierno de Rosas, y complementada con la actividad legislativa. Participó en la redacción de códigos, acuerdos y leyes, siendo su obra más reconocida el Código Civil de la República. Hacia 1852 Vélez Sársfield ya era reconocido, aun por el mismo Urquiza que lo convocó entre los “notables” a la reunión del 5 de mayo en Palermo, por su competencia jurídica. A los cincuenta y dos años de edad, su argumentación se apoya "naturalmente” en las herramientas que le ha proporcionado su trayectoria jurídica.

Mitre, en cambio, que fuera de su formación sistemática en la Academia Militar de Montevideo fue un autodidacta, desde los dieciséis años desarrolló de manera simultánea dos líneas de actividades que serían predominantes hasta 1852 en que comenzó una nueva: la legislativa. Estas líneas fueron la de militar y escritor, fundamentalmente como periodista. Hasta fines de 1847 su vida estuvo más ligada a su suerte militar, que lo llevó a Bolivia a principios de 1847, de donde fue expulsado a fines del mismo año. Llegó a Chile el 24 de abril de 1848, luego de pasar por Lima. La estadía en Chile estuvo marcada de manera excluyente por la actividad periodística y, desde la misma, política. En efecto, estuvo directamente vinculado, como redactor de El Comercio de Valparaíso, fundado por Alberdi, en la disputa por la presidencia de la república entre los conservadores y los liberales. El diario, y Mitre mismo, adoptaron una posición abierta y combativa en pro de las ideas liberales; Mitre incluso fue expulsado a Perú donde estuvo entre abril y junio de 1851. Su trayectoria lo diferencia claramente de Vélez Sársfield y hace comprensible que en su discurso para fundamentar la oposición al Acuerdo de San Nicolás recurra más bien a principios y convicciones liberales que a lo jurídico. Por otra parte, las ideas y valores incorporados en el ámbito militar, más relacionados con el orden, la disciplina, la conducción, no le proporcionaban buenos recursos a quien, distante de Urquiza que encarnaba tales principios, debía fundamentar su oposición al Acuerdo que los legitimaba.

Mitre y Vélez se posicionan en la dimensión del deber ser, pero se diferencian entre sí por la manera de organizar su propio discurso, recurriendo a principios el primero, y 
focalizando más el segundo en el conocimiento de los antecedentes legales. López, en cambio, apoyado en un deber ser superior como el establecido por un pacto fundamental, y habiendo afirmado la inexistencia de leyes que rijan la organización nacional, defiende los hechos consumados. Contra la anarquía, dispersión, ruptura del orden como consecuencia de acciones apasionadas y actitudes localistas, López propone la alianza entre la opinión ilustrada y la fuerza que se ha impuesto en Caseros, frente a la fórmula "nosotros sin (o en contra de) Urquiza” implícitamente defendida por los legisladores.

A los efectos de comprender y explicar la diversidad y características de los discursos analizados, hemos propuesto en este trabajo la construcción del lugar desde donde lo producen los agentes sociales teniendo en cuenta tres niveles:

$\varnothing$ oposición entre Buenos Aires y el interior del país

$\varnothing$ distancia de cada uno de los agentes en relación a Urquiza

$\varnothing$ trayectoria de cada agente

Este modo de proceder nos ha permitido fundar la hipótesis según la cual las tomas de posición a favor o en contra del Acuerdo de San Nicolás no serían producto de los principios, convicciones o legalidad invocados, sino de la posición de proximidad / distancia de cada uno de los agentes en relación a quien detenta el poder en el momento: Urquiza. Las formas de argumentación empleadas, más que fundantes de la decisión, constituirían estrategias discursivas de legitimación de la misma.

Entre tales estrategias hemos mencionado algunas como la atribución de género -tratado o acuerdo- al texto firmado por los gobernadores, que se vincula directamente con la definición de fronteras territoriales y, desde allí, con la delimitación de las facultades otorgadas por la ley para firmar un acuerdo o tratado. Aunque Vélez Sársfield sea ambiguo en la caracterización del documento, defiende, en todos los casos, la soberanía de la provincia de Buenos Aires que exige su adhesión voluntaria y explícita a través de los legisladores en su condición de representantes legítimos del pueblo, tanto al Acuerdo como a la futura constitución. Vicente Fidel López, en cambio, y a partir de la afirmación de un pacto fundamental preexistente, considera el texto de San Nicolás como un decreto que lo reglamenta, con lo cual su firma es atribución del gobernador de la provincia y los futuros constituyentes también tienen facultades para sancionar la nueva constitución sin que sea necesario someterla a la aprobación de las provincias.

La visión de la historia nacional y las definiciones de los antivalores puestos en juego varían en los interlocutores. Para Mitre y Vélez, los males de la República se deben al despotismo y tiranía de quienes concentraron y abusaron del poder; el uso de la fuerza militar fue indispensable para vencer a Rosas, pero esta debe ser sustituida por la razón y las ideas de quienes detentan una autoridad legitimada por las decisiones populares, aunque estas sean, en los hechos, orientadas por los artículos periodísticos de la misma elite ilustrada que convoca al pueblo al recinto. Para López, el caos nacional se debe a la anarquía, causa también del surgimiento de tiranos como Rosas y que requiere de la confluencia de la razón y de la fuerza; ellas permitirán superar la falta de vínculos y cohesión en la opinión pública.

La rivalidad y puja de intereses existentes entre Buenos Aires y las provincias del interior, de la cual dan cuenta los historiadores, constituyen la base a partir de la cual se hacen comprensibles características del Acuerdo mismo que se presenta como el modo 
legítimo y eficaz de lograr la organización nacional. También reaparece explícitamente en la argumentación de los agentes como cuando Vicente Fidel López dice que en la Sala "se acude al lenguage de las pasiones provinciales, siempre ciegas e injustas” (379), para luego afirmar: "El provincialismo, Señores, es hoy un absurdo" (381).

Sin embargo, esta rivalidad no resulta suficiente para fundar el hecho de que cada uno de los agentes considerados haya tomado respecto al Acuerdo la posición adoptada. Rechazo del exceso de autoridad que concede el Acuerdo a Urquiza, disimulado tras un discurso que manifiesta la fe en su persona en unos, los excluidos; defensa de la fuerza militar como instrumento para la organización nacional en quienes integran el círculo de los próximos al general. Las posiciones defendidas son coherentes con el lugar que se ocupa en relación al poder. En relación a quien, luego de disolver la Sala de Representantes que rechazaba el Acuerdo y anunciar que asume la gobernación de la provincia dice, en su comunicado: “[...] este estado de cosas es completamente anárquico, y en esta persuación me hallo plenamente autorizado para llenar la primera de mis obligaciones, que es salvar la patria de la demagogia, después de haberla libertado de la tiranía” (400).

\section{BiBLIOGRAFÍA}

Bourdieu, Pierre. Las reglas del arte. Barcelona: Anagrama, 1995.

Burgin, Miron. Aspectos económicos del federalismo argentino. Buenos Aires: Solar/ Hachette, 1975.

Cárcano, Ramón J. De Caseros al 11 de septiembre (1851-1852). Buenos Aires: Librería Mendesky, 1918.

Certeau, Michel de. La escritura de la historia. México: Universidad Iberoamericana, 1993.

Cortés Conde, Roberto y otros. "Las finanzas públicas y la moneda en las provincias del interior (1810-1860)”. Nueva historia de la nación argentina. Vol. 5: La configuración de la república independiente (1810-1914). Buenos Aires: Planeta, 2000. 507-26.

Costa, Ricardo L. y Danuta Teresa Mozejko. El discurso como práctica. Lugares desde donde se escribe la historia. Rosario: Homo Sapiens, 2001.

Cháneton, Abel. Historia de Vélez Sársfield. Buenos Aires: Librería y Editorial "La Facultad”, 1938.

Chiaramonte, José Carlos. Ciudades, provincias, Estados: orígenes de la nación Argentina (1800-1846). Buenos Aires: Ariel, 1997.

“En torno a los orígenes de la nación argentina”. Para una historia de América II. Los nudos (1). México: El Colegio de México, Fideicomiso Historia de las Américas, FCE, 1999. 286-317.

Dahrendorf, Ralf. Class and Class Conflict in an Industrial Society. London: Routledge \& Kegan Paul, 1959.

De Marco, Miguel Ángel. Bartolomé Mitre. Buenos Aires: Planeta, 1998.

Goffman, Erwin. Ritual de la interacción. Buenos Aires: Tiempo Contemporáneo, 1970.

Gorostegui de Torres, Haydée. Argentina. La organización nacional. Buenos Aires: Paidós, 1972. 
Halperín Donghi, Tulio. Proyecto y construcción de una nación (1846-1880). Buenos Aires: Ariel, 1995.

Oszlak, Oscar. La formación del Estado argentino. Buenos Aires: Planeta, 1997.

Piccirilli, Ricardo. Los López. Una dinastía intelectual. Buenos Aires: EUDEBA, 1972.

Ravignani, Emilio. Asambleas constituyentes argentinas. Tomo IV. Buenos Aires: Peuser, 1937.

Sábato, Hilda. La política en las calles. Entre el voto y la movilización. Buenos Aires 1862-1880. Buenos Aires: Sudamericana, 1998.

“Vida política y cultura de la movilización en Buenos Aires, 1860-1880”. Para una historia de América III. Los nudos (2). México: El Colegio de México, Fideicomiso Historia de las Américas, FCE, 1999. 482-512.

Saussure, Ferdinand de. Curso de lingüística general. Buenos Aires: Losada, 1961.

Weber, Max. Economía y sociedad. México: FCE, 1969. 